\title{
BIOMASSA RADICULAR DA CULTURA DE CANA-DE-AÇÚCAR EM SISTEMA CONVENCIONAL E PLANTIO DIRETO COM E SEM CALCÁRIO(1)
}

\author{
Tadeu Nascimento Cury ${ }^{(2)}$, Isabella Clerici De Maria ${ }^{(3)} \&$ Denizart Bolonhezi $^{(4)}$
}

\begin{abstract}
RESUMO
O sistema de plantio pode influenciar atributos físicos e químicos do solo, alterando o desenvolvimento das raízes das culturas. $O$ objetivo deste trabalho foi avaliar o efeito do sistema plantio direto (PD) e o do preparo convencional (PC) e o uso de calcário (0 e $\left.2,0 \mathrm{t} \mathrm{ha}^{-1}\right)$ no sistema radicular da cana-de-açúcar. Este estudo foi realizado em Latossolo Vermelho eutroférrico, em experimento de longa duração, iniciado em 1998, após três ciclos de quatro anos com colheita sem queima da palha. Foram realizadas coletas de amostras de solo para avaliação de alguns atributos físicos (densidade, porosidade e resistência à penetração) e de fertilidade do solo. Para a coleta de raízes, foi utilizada sonda amostradora em quatro épocas definidas pelo balanço hídrico da região, sendo a amostragem realizada em seis pontos equidistantes à linha da soqueira, em camadas de $0,20 \mathrm{~m}$ até $1,0 \mathrm{~m}$ de profundidade. $\mathrm{O} P D$ e o uso de calcário resultaram em valores mais elevados dos atributos relacionados à aplicação do calcário, como V\% e teores de $\mathrm{Ca}$, apenas na camada superficial. Os valores de densidade e resistência foram mais elevados no PD e na entrelinha. Na linha de plantio, não houve diferença entre os tratamentos. A cana-de-açúcar manteve, em média, cerca de $4,0 \mathrm{t} \mathrm{ha}^{-1}$ de raízes no solo na camada até $1,0 \mathrm{~m}$ de profundidade. Houve diferença significativa entre as camadas e as posições de amostragem e, embora as raízes da cana-de-açúcar se concentrem na superfície e próximo da soqueira, 25 a $30 \%$ das raízes estão na entrelinha $(0,6 \mathrm{~m}$ da soqueira) e 15 a $30 \%$ estão abaixo de $0,60 \mathrm{~m}$, indicando que as raízes da cana-deaçúcar exploram grande volume de solo. A variação na quantidade de raízes foi mais influenciada pela condição hídrica do solo do que pelas práticas de manejo. A maior quantidade de raiz foi determinada no máximo excedente hídrico; e a menor, na época de reposição hídrica do solo. As maiores variações na quantidade de
\end{abstract}

(1) Parte da Dissertação de Mestrado do primeiro autor apresentada ao Curso de Pós-Graduação em Agricultura Tropical e Subtropical, Instituto Agronômico (IAC). Recebido para publicação em 10 de julho de 2013 e aprovado em 25 de julho de 2014.

${ }^{(2)}$ Mestre em Agricultura Tropical e Subtropical, IAC. Av. Barão de Itapura, 1481. Caixa Postal 28. CEP 13012-970 Campinas (SP). Bolsista da Capes. E-mail: tadeucury@gmail.com

(3) Pesquisadora Científica, IAC. Bolsista CNPq/PQ. E-mail: icdmaria@iac.gov.br

(4) Pesquisador Científico, APTA-Ribeirão Preto. Av. Bandeirantes, 2419. CEP 14030-670 Ribeirão Preto (SP). Bolsista do CNPq/ DT-2. E-mail: denizart@apta.sp.gov.br 
raízes entre épocas foram observadas no PC e sem aplicação de calcário. Os tratamentos PD e com calcário mantiveram a massa radicular com menor variação ao longo das épocas de amostragem. As alterações físicas e químicas do solo por influência do PD e calcário não foram suficientes para alterar significativamente o desenvolvimento do sistema radicular da cana-de-açúcar.

Termos de indexação: plantio direto, calagem, raízes, Saccharum spp.

\title{
SUMMARY: SUGARCANE ROOT BIOMASS IN NO-TILLAGE AND CONVENCIONAL SYSTEMS WITH AND WITHOUT LIMING
}

\begin{abstract}
The cultivation system can influence physical and chemical soil properties by changing the root development of crops. The aim of this study was to evaluate the effect of no-tillage

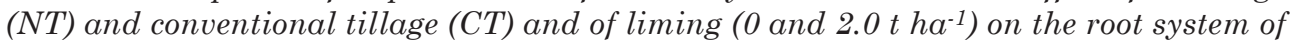
sugarcane. The study was conducted on an Oxisol in a long-term experiment initiated in 1998, after three sugarcane cycles of four years without burning the cane trash at harvest. The soil was sampled to evaluate some physical properties (density, porosity and penetration resistance) and soil fertility. Roots were sampled with a probe, in four seasons defined by the regional soil water balance, at six sampling points equidistant from the crop rows, in $0.20 \mathrm{~m}$ layers down to a depth of $1.0 \mathrm{~m}$. As a result, no-tillage with liming resulted in highest values of the liming-related properties, such as base saturation and calcium concentrations in the surface layer only. Soil density and soil resistance were highest under no-tillage and between the rows. In the crop row there was no difference among treatments. On average, about $4.0 \mathrm{Mg} \mathrm{ha} \mathrm{M}^{-1}$ of sugarcane roots remained in the soil layer to a depth of $1.0 \mathrm{~m}$. The differences among layers and sampling positions were significant, and although the sugarcane roots were concentrated at the surface and near the crop rows, 25-30\% of the roots were in the interrows (0.6 m away from the row) and 15-30\% below $0.60 \mathrm{~m}$, indicating that sugarcane roots explore a large soil volume. The variation in the root biomass was more influenced by crop growth and soil water status than by management practices. The root biomass was largest at the maximum water surplus and lowest at the time of soil water recharge. The largest variations in the root biomass between seasons were observed in the conventional system without liming. In the no-tillage treatments with liming the root mass varied little with sampling times. The changes in physical and chemical soil properties under the influence of no-tillage and limestone were not sufficient to significantly affect the development of the sugarcane root system.
\end{abstract}

Index terms: no-tillage, liming, root, Saccharum sp.

\section{INTRODUÇÃO}

A agricultura conservacionista tem como alicerce o mínimo revolvimento do solo, a manutenção de resíduos na superfície e o uso de rotação de culturas (Derpsch et al., 2011). O sistema plantio direto apresenta esses princípios e compreende aproximadamente 25 milhões de hectares com produção de grãos no Brasil; porém, é muito pouco utilizado na cultura da cana-de-açúcar. Entretanto, no início da década de 1980, a cana-de-açúcar foi uma das primeiras culturas a testar o herbicida glifosato, com finalidade de reduzir operações de preparo do solo, sistema conhecido como cultivo mínimo (Mutton, 1983; Stolf, 1985; Casagrandi, 1988; Conde \& Donzelli, 1997; Torres \& Villegas, 1998).

Em termos gerais, o sistema radicular de cana-deaçúcar pode atingir entre 2 e $6 \mathrm{~m}$ de profundidade, renova-se após a colheita e apresenta a biomassa concentrada nas camadas superficiais $(0,00-0,40 \mathrm{~m})$. Para as condições brasileiras, os poucos estudos sobre raízes em cana-de-açúcar foram realizados, em manejo de solo convencional (Vasconcelos, 2002; Cintra et al., 2006; Faroni \& Trivelin, 2006), e são escassos os resultados sobre a influência do manejo de solo no crescimento radicular da cana-de-açúcar. Entre as dúvidas sobre a viabilidade de adoção do plantio direto para cana-de-açúcar, estão a aplicação de calcário na superfície e o impacto da compactação do solo sobre o desenvolvimento do sistema radicular.

Apesar da importância dos benefícios do uso do calcário e de sistemas de manejo reduzido, como o plantio direto, para a cana-de-açúcar há poucas informações quanto aos efeitos de sistemas de manejo e às doses de calcário sobre a biomassa de raiz da cana-de-açúcar. Por causa do menor revolvimento do solo, da maior compactação e da aplicação do calcário em superfície, o sistema radicular no sistema de 
manejo plantio direto poderia ser reduzido em comparação com o sistema convencional.

Segundo Otto et al. (2009), estudos relacionados à distribuição de raiz no perfil do solo podem ser úteis por uma série de razões, como a recomendação para localização de fertilizantes para soqueira, controle de pragas que atacam o sistema radicular, regulagem de tráfego de máquinas na operação de colheita, entre outros.

O objetivo deste trabalho foi quantificar a biomassa do sistema radicular da cana-de-açúcar implantada nos sistemas de manejo convencional e plantio direto com duas doses de calcário, para o melhor entendimento da dinâmica radicular, que está intimamente ligada à produtividade da parte aérea, que é o interesse econômico da cana-de-açúcar.

\section{MATERIAL E MÉTODOS}

O experimento, iniciado em 1998, foi instalado na Estação Experimental do Instituto Agronômico de Campinas - IAC, localizada em Ribeirão Preto, SP, atualmente denominada APTA Centro-Leste, em Latossolo Vermelho eutroférrico textura muito argilosa, conforme Sistema Brasileiro de Classificação de Solos (Santos et al., 2006). A área onde o experimento foi instalado apresentava histórico de três ciclos de quatro anos com colheita sem queima prévia da palha. Cada ciclo do canavial foi de quatro cortes consecutivos, sendo o plantio feito em sistema de cana de ano com cultivo de soja no verão anterior. Utilizou-se espaçamento de $1,50 \mathrm{~m}$ entre sulcos de plantio. A canade-açúcar cultivada foi o clone IAC SP95-5000.

As adubações foram feitas de acordo com os resultados de análise de solo e conforme a necessidade da cultura, seguindo as recomendações de Raij et al. (1996). O controle de plantas daninhas foi feito por herbicidas seletivos de pré-emergência, além de algumas capinas nas parcelas quando necessárias.

Utilizou-se delineamento experimental em blocos ao acaso, com parcelas subdivididas e quatro repetições. As parcelas foram constituídas pelos dois sistemas de manejo do solo na reforma do canavial: plantio direto (PD) e plantio com preparo convencional (PC). As subparcelas receberam dois tratamentos: sem calcário $\left(0 \mathrm{t} \mathrm{ha}^{-1}\right)$ e com calcário $\left(2,0 \mathrm{t} \mathrm{ha}^{-1}\right)$.

Na reforma do canavial, no sistema $\mathrm{PD}$, a soqueira foi erradicada com 6,0 $\mathrm{L} \mathrm{ha}^{-1}$ de glifosato $\left(360 \mathrm{~g} \mathrm{~L}^{-1}\right)$. No sistema convencional, a soqueira foi destruída mecanicamente, e o solo foi preparado com arado de aivecas na camada média de $30 \mathrm{~cm}$, seguido de duas gradagens niveladoras, com discos de $20^{\circ}$. O calcário foi aplicado nas subparcelas correspondentes ao tratamento com calcário $\left(2,0 \mathrm{t} \mathrm{ha}^{-1}\right)$, permanecendo em superfície no PD e sendo incorporado ao solo no PC. Após o preparo, a área foi cultivada com soja; e após a colheita da soja, foi feita a sulcação e o plantio dos toletes de cana-de-açúcar.

As subparcelas experimentais foram dimensionadas para total mecanização das operações e apresentavam $20 \times 15 \mathrm{~m}$.

As avaliações foram realizadas após o primeiro corte da cana-de-açúcar em quatro épocas: Época 1 - entre $1^{\circ}$ de agosto a $1^{\circ}$ de setembro de 2011 (máximo déficit hídrico); Época 2 - entre 15 de outubro a 15 de novembro de 2011 (início reposição hídrica); Época 3 - entre $1^{\circ}$ de janeiro a $1^{\circ}$ de fevereiro de 2012 (máximo excedente hídrico) e Época 4 - entre 15 de março a 15 de abril de 2012 (início déficit hídrico).

Para quantificação da biomassa de raízes, foi utilizada sonda amostradora de raízes fabricada em aço inox, pela Sondaterra, com volume de coleta de $475,17 \mathrm{~cm}^{3}$, a cada $20 \mathrm{~cm}$ de camada de sondagem. Em cada amostragem, foram coletadas raízes em seis pontos adjacentes à linha da soqueira, em cinco camadas: $0,00-0,20 ; 0,20-0,40 ; 0,40-0,60 ; 0,60-0,80$; e 0,80-1,00 m. Os pontos eram distribuídos da seguinte forma: três pontos localizados do lado direito, e três pontos, do lado esquerdo da soqueira, sendo o $1^{\circ}$ ponto rente ao lado direito ou esquerdo da soqueira (1D e $1 \mathrm{E}), \mathrm{o} 2^{\circ}$ ponto $30 \mathrm{~cm}$ em relação ao $1^{\circ}$ ponto $(2 \mathrm{D}$ e $2 \mathrm{E})$ e o $3^{\circ}$ ponto soma-se $30 \mathrm{~cm}$ em relação ao $2^{\circ}$ ponto (3D e $3 \mathrm{E})$.

Ao volume de solo coletado pela sonda foi acrescentado $200 \mathrm{~mL}$ de solução 10 \% de água e álcool, com a finalidade de conservar as raízes e auxiliar na dispersão da argila para facilitar a separação solo-raiz. Após o repouso de $1 \mathrm{dia}$, as amostras foram lavadas em água corrente, separando as raízes em peneira de $0,5 \mathrm{~mm}$ de cobertura. Com o auxílio de pinça cirúrgica, as raízes, ainda úmidas, foram separadas de eventuais materiais ou sujeiras. As raízes, já separadas, foram então guardadas em envelopes de papel e colocadas em estufa de secagem a $60^{\circ} \mathrm{C}$, durante tempo mínimo de $48 \mathrm{~h}$.

Após seco, o material foi pesado em balança digital com precisão de $0,01 \mathrm{~g}$. Para determinar os valores de biomassa radicular em t ha-1, o cálculo levou em consideração o volume coletado pela sonda $\left(475,17 \mathrm{~cm}^{3}\right)$ e o volume de solo de cada camada amostrada, somandose a quantidade de biomassa radicular de todas as camadas de solo $(0,00-0,20 ; 0,20-0,40 ; 0,40-0,60 ; 0,60$ 0,80; e 0,80-1,00 m).

A resistência à penetração foi determinada por meio de penetrômetro de impacto (modelo IAA/Planalsucar STOLF), conforme método proposto por Stolf (1991), na $3^{\mathrm{a}}$ e $4^{\mathrm{a}}$ épocas de amostragem do sistema radicular. Foram feitos dois pontos de amostragens por parcela, sendo um na linha e outro na entrelinha da cana-deaçúcar, resultando em 16 medições de resistência à penetração por tratamento experimental. A leitura da medida da penetração foi feita a cada batida no penetrômetro de impacto. 
A avaliação dos atributos físicos do solo, densidade do solo, porosidade total, macroporosidade e microporosidade, foi feita de acordo com Camargo et al. (1986), utilizando-se anéis volumétricos com borda cortante de $0,0001 \mathrm{~m}^{3}$ de volume, nas épocas 3 e 4 , para coleta das amostras indeformadas. A densidade do solo (Ds) foi determinada pela massa de solo seco em estufa a $105-110{ }^{\circ} \mathrm{C}$, sendo os valores expressos em $\mathrm{kg} \mathrm{dm}^{-3}$. A porosidade total (PT) foi determinada pela quantidade de água do solo saturado; e a microporosidade (Mi), pela água retida a uma tensão de $6 \mathrm{kPa}$, sendo os valores expressos em $\mathrm{m}^{3} \mathrm{~m}^{-3}$. A macroporosidade (Ma) é a diferença entre a porosidade total e microporosidade. Foram feitos dois pontos de amostragem por parcela, sendo um na linha e outro na entrelinha da cana-de-açúcar. As amostras foram coletadas em cinco camadas: $0,00-0,05 ; 0,05-0,10$; 0,10-0,20; 0,20-0,40; e 0,40-0,60 m.

Para análise de fertilidade, o solo foi coletado com uma sonda de aço inox, com compartimento de coleta a cada $0,10 \mathrm{~m}$ ao longo do instrumento. A retirada das amostras de solo foi feita durante a $2^{\mathrm{a}}$ época de amostragem. As subamostras foram misturadas em um balde devidamente limpo para formar as amostras compostas representativas das camadas de 0,00-0,20, 0,20-0,40 e 0,40-0,60 m. No laboratório, as determinações seguiram os procedimentos descritos por Raij et al. (2001): carbono orgânico por oxidação úmida e determinação colorimétrica para quantificar o teor de matéria orgânica (MO); e resina trocadora de íons para extração de $\mathrm{P}$, Ca e demais cátions utilizados para cálculo da soma de bases, da capacidade de troca catiônica e da saturação por bases (V\%), sendo a leitura dos teores feita por espectrofotometria de emissão atômica por plasma (ICP/AES).

Os resultados de peso da biomassa de raízes, da resistência à penetração, da densidade do solo, da porosidade total, da macroporosidade e dos atributos da fertilidade do solo foram analisados estatisticamente pelo programa SISVAR (Ferreira, 2008), em esquema fatorial $2 \times 2$. Para os atributos físicos, a posição de amostragem (linha ou entrelinha) foi considerada mais um fator e analisada como um fatorial $2 \times 2 \times 2$. As médias foram comparadas pelo teste de Tukey a $10 \%$.

\section{RESULTADOS E DISCUSSÃO}

A análise dos atributos físicos do solo indicou que não houve interação entre os fatores estudados e que, de forma geral, não houve diferença entre os tratamentos para Ds, PT e Mi (Quadro 1), inclusive entre as posições linha e entrelinha. Houve diferença significativa apenas nas camadas de 0,00-0,05 e 0,10$0,20 \mathrm{~m}$ para a Ds, com valores mais elevados no sistema plantio direto (PD) na camada de 0,00-0,05 $\mathrm{m}$ e no preparo convencional (PC) na camada de 0,10 -
0,20 m, correspondendo aos maiores valores observados, de $1,33 \mathrm{~kg} \mathrm{dm}^{-3}$. Camilotti et al. (2005), estudando o efeito de diferentes sistemas de manejo, incluindo um preparo convencional e um sistema de cultivo mínimo apenas com destruição de soqueira, em Latossolo Vermelho, também não observaram diferenças significativas entre tratamentos em atributos do solo como Ds e PT. Em estudo sobre a compactação do solo e a brotação das soqueiras de canade-açúcar, Fernandes et al. (1983) observaram que, em densidades superiores a $1,45 \mathrm{~kg} \mathrm{dm}^{-3}$, as raízes não encontram condições de suprir a parte aérea das plantas com nutrientes em níveis satisfatórios. Neste trabalho, não foram encontrados valores superiores a esses e, portanto, a Ds não se apresentou limitante para o sistema radicular.

As diferenças na Ds se refletiram significativamente nos valores de PT e Mi. Com o revolvimento do solo no PC, há redução da Ds e aumento da PT, com redução da Mi (Hill \& Cruse, 1985). Os implementos de preparo, entretanto, podem criar camadas mais adensadas em subsuperfície (camada de 0,10-0,20 m) com aumento da Ds, redução da PT e aumento dos microporos. Na superfície, o PD, além de reduzir a PT, altera a distribuição do tamanho dos poros, com redução dos poros de maior tamanho (Ouwerkerk \& Boone, 1970; Tormena et al., 2002). A Ma, diferença entre a PT e a Mi (Quadro 1), apresentou valores sempre maiores que $0,10 \mathrm{~m}^{3} \mathrm{~m}^{-3}$, não apresentando limitação ao desenvolvimento das raízes.

A resistência à penetração (Figuras 1 e 2) foi significativamente maior no tratamento $\mathrm{PD}$, na posição entrelinha, e na época 4 (início do déficit hídrico), entre 0,10 e $0,40 \mathrm{~m}$. A maior resistência mecânica do solo à penetração deve-se ao não revolvimento do solo, que ano após ano acumula pressões pelo tráfego de máquinas e, ainda, pela acomodação natural das partículas (Carvalho Júnior et al., 1998). Silva et al. (2000), em estudo sobre a resistência mecânica do solo à penetração influenciada pelo tráfego de uma colhedora de grãos em dois sistemas de manejo do solo, observaram que na camada superficial houve maior resistência à penetração na linha do tráfego, tanto no preparo reduzido como em sistema plantio direto. $\mathrm{O}$ tráfego de máquinas nessa camada, causando maior resistência na entrelinha, em ambos os tipos de plantio e tratamentos de calcário, evidencia a importância do tráfego da colhedora no aumento da compactação do solo.

$\mathrm{Na}$ posição linha, não houve diferença entre os tratamentos, nas duas épocas avaliadas, considerando o PD e o PC, assim como com e sem calcário, indicando que a sulcação cria ambiente com menor resistência à penetração, independentemente do sistema de manejo.

Também para os atributos da fertilidade do solo, a análise estatística indicou que não há interação entre os fatores estudados (manejo e calcário). De modo 
Quadro 1. Valores de densidade do solo (Ds), de porosidade do solo (PT) e de microporosidade do solo (Mi) por camada de solo sem calcário (C0) e com $2,0 \mathrm{t} \mathrm{ha}^{-1}$ de calcário (C1), nos tratamentos plantio direto (PD) e plantio convencional (PC) e nas posições linha e entrelinha

\begin{tabular}{|c|c|c|c|c|c|}
\hline Fator & $0,00-0,05 \mathrm{~m}$ & $0,05-0,10 \mathrm{~m}$ & $0,10-0,20 \mathrm{~m}$ & $0,20-0,40 \mathrm{~m}$ & $0,40-0,60 \mathrm{~m}$ \\
\hline & & & Ds, $\mathrm{kg} \mathrm{dm}^{-3}$ & & \\
\hline \multicolumn{6}{|l|}{ Calagem } \\
\hline $\mathrm{C} 0$ & $1,10 \mathrm{~b}$ & $1,13 \mathrm{a}$ & $1,28 \mathrm{a}$ & $1,24 \mathrm{a}$ & $1,23 \mathrm{a}$ \\
\hline $\mathrm{C} 1$ & $1,05 \mathrm{a}$ & $1,12 \mathrm{a}$ & $1,29 \mathrm{a}$ & $1,23 \mathrm{a}$ & $1,24 \mathrm{a}$ \\
\hline \multicolumn{6}{|l|}{ Manejo } \\
\hline PD & $1,11 \mathrm{~b}$ & $1,12 \mathrm{a}$ & $1,23 \mathrm{a}$ & $1,23 \mathrm{a}$ & $1,22 \mathrm{a}$ \\
\hline $\mathrm{PC}$ & $1,04 \mathrm{a}$ & $1,13 \mathrm{a}$ & $1,33 \mathrm{~b}$ & $1,24 \mathrm{a}$ & $1,24 \mathrm{a}$ \\
\hline \multicolumn{6}{|l|}{ Posição } \\
\hline Linha & $1,07 \mathrm{a}$ & $1,13 \mathrm{a}$ & $1,30 \mathrm{a}$ & $1,20 \mathrm{a}$ & $1,25 \mathrm{a}$ \\
\hline \multirow[t]{2}{*}{ Entrelinha } & $1,08 \mathrm{a}$ & $1,12 \mathrm{a}$ & $1,27 \mathrm{a}$ & $1,26 \mathrm{~b}$ & $1,21 \mathrm{a}$ \\
\hline & & & $\mathrm{PT}, \mathrm{m}^{3} \mathrm{~m}^{-3}$ & & \\
\hline \multicolumn{6}{|l|}{ Calagem } \\
\hline C0 & $0,652 \mathrm{a}$ & $0,637 \mathrm{a}$ & $0,606 \mathrm{a}$ & $0,612 \mathrm{a}$ & $0,609 \mathrm{a}$ \\
\hline $\mathrm{C} 1$ & $0,648 \mathrm{a}$ & $0,637 \mathrm{a}$ & $0,605 \mathrm{a}$ & $0,617 \mathrm{a}$ & $0,608 \mathrm{a}$ \\
\hline \multicolumn{6}{|l|}{ Manejo } \\
\hline PD & $0,642 \mathrm{a}$ & $0,635 \mathrm{a}$ & $0,628 \mathrm{~b}$ & $0,617 \mathrm{a}$ & $0,612 \mathrm{a}$ \\
\hline PC & $0,659 \mathrm{~b}$ & $0,638 \mathrm{a}$ & $0,583 \mathrm{a}$ & $0,612 \mathrm{a}$ & $0,606 \mathrm{a}$ \\
\hline \multicolumn{6}{|l|}{ Posição } \\
\hline Linha & $0,655 \mathrm{a}$ & $0,637 \mathrm{a}$ & $0,607 \mathrm{a}$ & 0,615 a & $0,608 \mathrm{a}$ \\
\hline \multirow[t]{2}{*}{ Entrelinha } & $0,645 \mathrm{a}$ & $0,636 \mathrm{a}$ & $0,605 \mathrm{a}$ & $0,614 \mathrm{a}$ & $0,609 \mathrm{a}$ \\
\hline & & & $\mathrm{Mi}, \mathrm{m}^{3} \mathrm{~m}^{-3}$ & & \\
\hline \multicolumn{6}{|l|}{ Calagem } \\
\hline $\mathrm{C} 0$ & $0,366 \mathrm{a}$ & $0,377 \mathrm{a}$ & $0,409 \mathrm{a}$ & $0,392 \mathrm{a}$ & $0,401 \mathrm{a}$ \\
\hline $\mathrm{C} 1$ & $0,361 \mathrm{a}$ & $0,372 \mathrm{a}$ & $0,416 \mathrm{a}$ & $0,396 \mathrm{a}$ & 0,399 a \\
\hline \multicolumn{6}{|l|}{ Manejo } \\
\hline $\mathrm{PD}$ & $0,360 \mathrm{a}$ & $0,364 \mathrm{a}$ & $0,396 \mathrm{a}$ & $0,396 \mathrm{a}$ & $0,397 \mathrm{a}$ \\
\hline $\mathrm{PC}$ & $0,367 \mathrm{a}$ & $0,385 \mathrm{~b}$ & $0,429 \mathrm{~b}$ & $0,392 \mathrm{a}$ & $0,404 \mathrm{a}$ \\
\hline \multicolumn{6}{|l|}{ Posição } \\
\hline Linha & $0,364 \mathrm{a}$ & $0,377 \mathrm{a}$ & $0,415 \mathrm{a}$ & $0,387 \mathrm{a}$ & $0,411 \mathrm{~b}$ \\
\hline Entrelinha & $0,363 \mathrm{a}$ & $0,373 \mathrm{a}$ & $0,410 \mathrm{a}$ & $0,402 \mathrm{~b}$ & $0,387 \mathrm{a}$ \\
\hline
\end{tabular}

As letras em cada coluna comparam os níveis de cada fator e, quando diferentes, indicam que os valores diferem pelo teste de Tukey a $10 \%$.

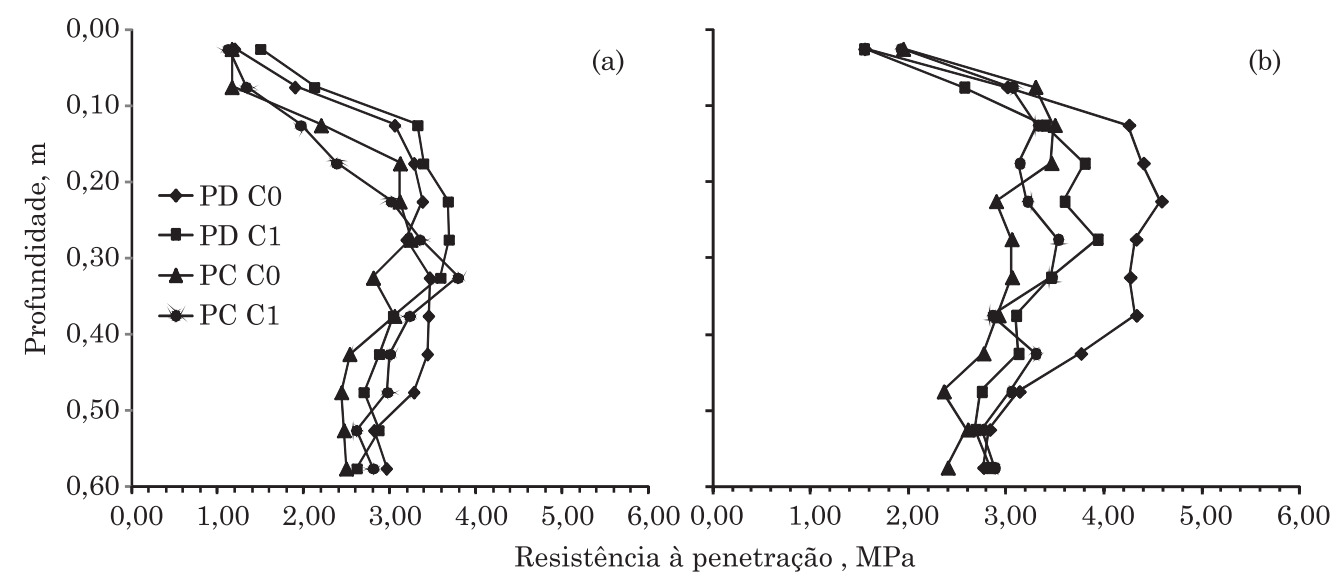

Figura 1. Valores da resistência à penetração por camada de solo nas posições linha (a) e entrelinha (b) na época de máximo excedente hídrico (Época 3), nos tratamentos plantio direto (PD), plantio convencional (PC), sem calcário (C0) e com 2,0 t ha-1 de calcário (C1). 


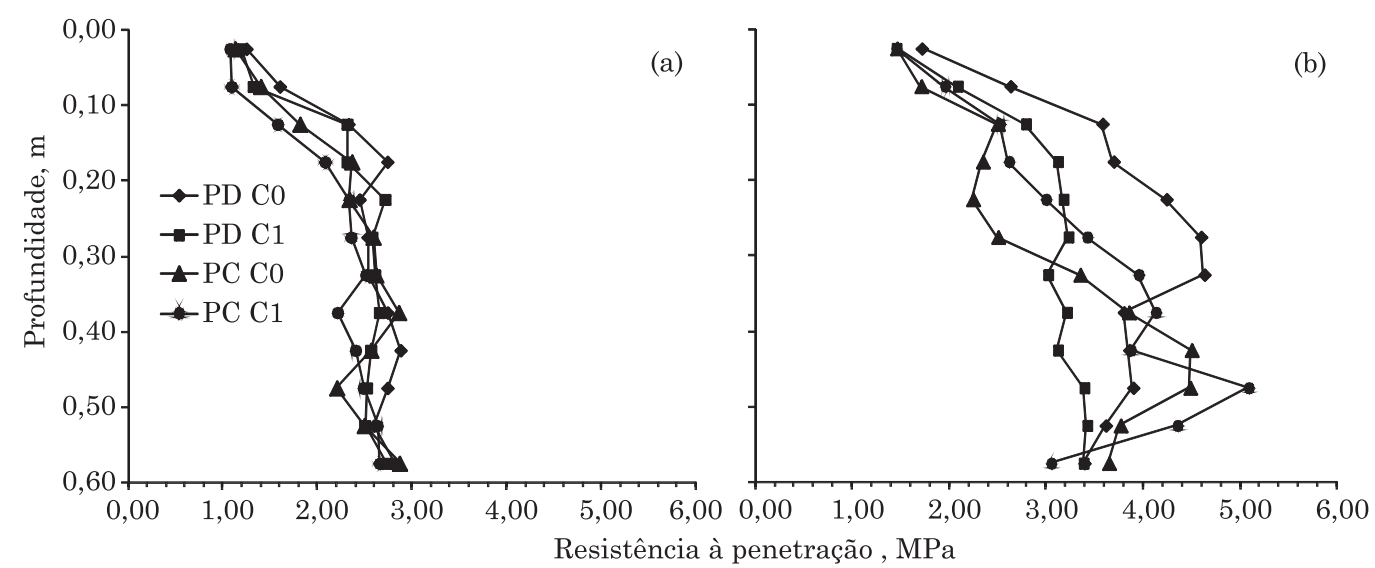

Figura 2. Valores da resistência à penetração por camada de solo nas posições linha (a) e entrelinha (b) na época de início do déficit hídrico (Época 4), nos tratamentos plantio direto (PD), plantio convencional (PC), sem calcário (C0) e com 2,0 t ha-1 de calcário (C1).

geral, as diferenças entre tratamentos ocorreram na camada de 0,00-0,20 m, com valores mais elevados de P, Ca e V\% para os tratamentos PD e C1 (Quadro 2). Mesmo com calcário sendo colocado em superfície no $\mathrm{PD}$, não houve diferença significativa entre os manejos nas camadas mais profundas, onde se esperava maiores teores de Ca para o PC.

Para a matéria orgânica, houve diferença significativa na camada de 0,20-0,40 m entre PD e $\mathrm{PC}$, este apresentando maior teor. Rheinheimer et al.

Quadro 2. Valores de matéria orgânica (MO), fósforo disponível (P), saturação por bases (V) e cálcio (Ca) por camada de solo sem calcário (C0) e com 2,0 t ha-1 de calcário (C1) nos tratamentos plantio direto (PD) e plantio convencional (PC)

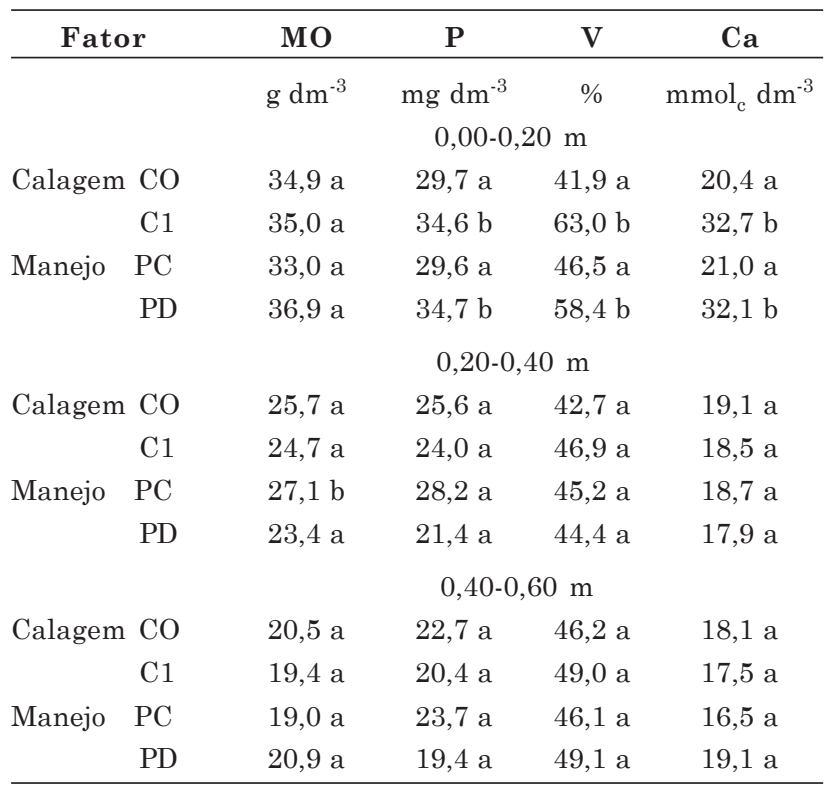

As letras em cada coluna comparam os níveis de cada fator e, quando diferentes, indicam que os valores diferem pelo teste de Tukey a $10 \%$.
(2000) observaram elevação do $\mathrm{pH}$ em $\mathrm{CaCl}_{2}$, dos teores de Ca e Mg trocáveis e diminuição do $\mathrm{Al}$ trocável na camada de 0,0-2,5 cm, com a aplicação superficial de calcário.

A cana-de-açúcar manteve, em média, cerca de $4,0 \mathrm{t} \mathrm{ha}^{-1}$ de raízes no solo na camada até $1,0 \mathrm{~m}$ de profundidade. Houve diferença significativa para biomassa de raízes entre as camadas e as posições de amostragem (Quadro 3). Embora as raízes da canade-açúcar se concentrem na superfície e próximo da soqueira, o sistema radicular explora grande volume de solo (Figuras 3 e 4). A camada até $0,40 \mathrm{~m}$ concentrou de 60 a $70 \%$ do total de raízes, mas na camada mais profunda, entre 0,60 e 1,00 m, foram observados 15 a $30 \%$ das raízes. Esses dados estão bastante próximos dos observados por Alvarez et al. (2000), os quais, trabalhando com cana crua e queimada, observaram de

Quadro 3. Biomassa de raízes por época de amostragem em cada camada e em cada posição em relação à soqueira na média dos tratamentos com e sem calcário e plantio direto e convencional, em Latossolo Vermelho férrico

\begin{tabular}{lllll}
\hline Fator & Época 1 & Época 2 & Época 3 & Época 4 \\
\cline { 2 - 5 } & \multicolumn{5}{c}{$\mathrm{t} \mathrm{ha}^{-1}$} \\
\cline { 2 - 5 } Profundidade & & & \\
$0,00-0,20 \mathrm{~m}$ & $1,258 \mathrm{~d}$ & $0,913 \mathrm{c}$ & $1,635 \mathrm{~d}$ & $1,519 \mathrm{c}$ \\
$0,20-0,40 \mathrm{~m}$ & $0,730 \mathrm{c}$ & $0,518 \mathrm{~b}$ & $0,753 \mathrm{c}$ & $0,646 \mathrm{~b}$ \\
$0,40-0,60 \mathrm{~m}$ & $0,436 \mathrm{~b}$ & $0,353 \mathrm{ab}$ & $0,574 \mathrm{bc}$ & $0,478 \mathrm{ab}$ \\
$0,60-0,80 \mathrm{~m}$ & $0,339 \mathrm{ab}$ & $0,271 \mathrm{a}$ & $0,335 \mathrm{ab}$ & $0,383 \mathrm{a}$ \\
$0,80-1,00 \mathrm{~m}$ & $0,225 \mathrm{a}$ & $0,265 \mathrm{a}$ & $0,255 \mathrm{a}$ & $0,335 \mathrm{a}$ \\
Posição & & & & \\
$0,00 \mathrm{~m}$ & $0,743 \mathrm{~b}$ & $0,539 \mathrm{~b}$ & $0,905 \mathrm{~b}$ & $0,947 \mathrm{~b}$ \\
$0,30 \mathrm{~m}$ & $0,591 \mathrm{a}$ & $0,433 \mathrm{ab}$ & $0,661 \mathrm{a}$ & $0,579 \mathrm{a}$ \\
$0,60 \mathrm{~m}$ & $0,459 \mathrm{a}$ & $0,423 \mathrm{a}$ & $0,566 \mathrm{a}$ & $0,490 \mathrm{a}$ \\
\hline
\end{tabular}

As letras em cada coluna comparam níveis dos fatores profundidade e posição, e, quando iguais, indicam que os valores não diferem pelo teste de Tukey a $10 \%$. 


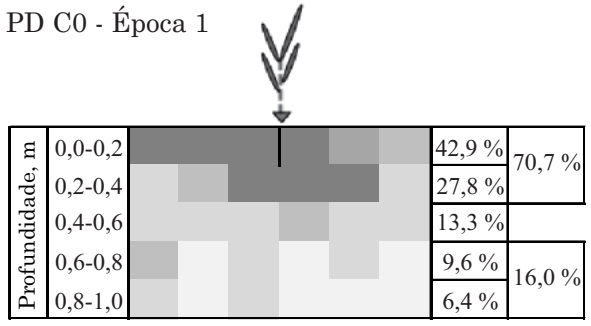

3 E 2 E 1 E 1 D 2 D 3 D

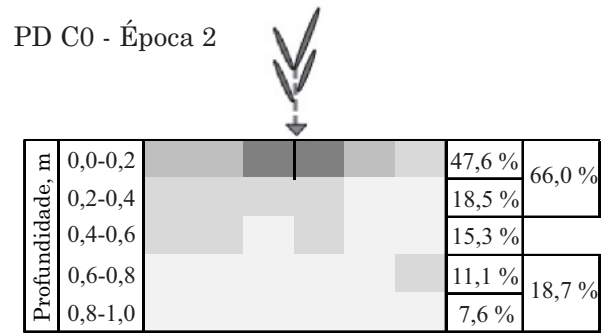

3 E 2 E 1 E 1 D 2 D 3 D
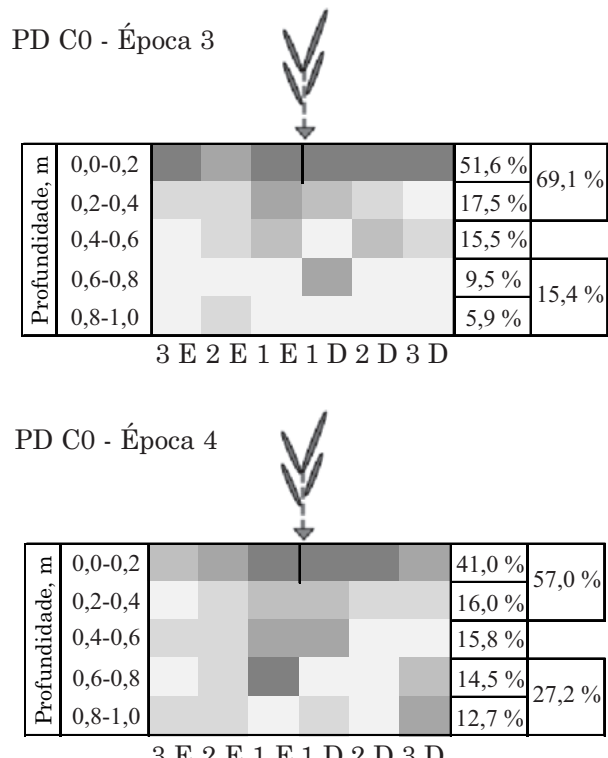

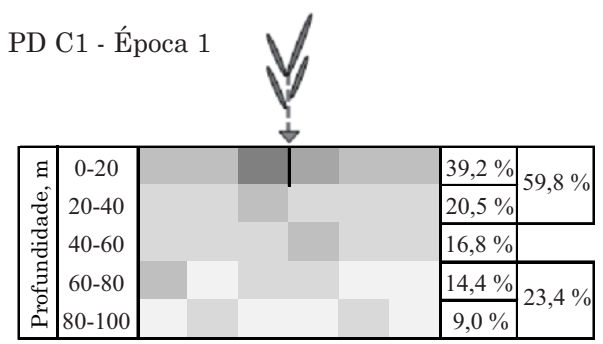

3 E 2 E 1 E 1 D 2 D 3 D

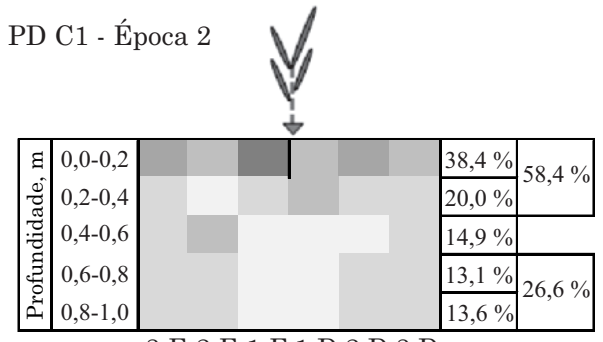

3 E 2 E 1 E 1 D 2 D 3 D
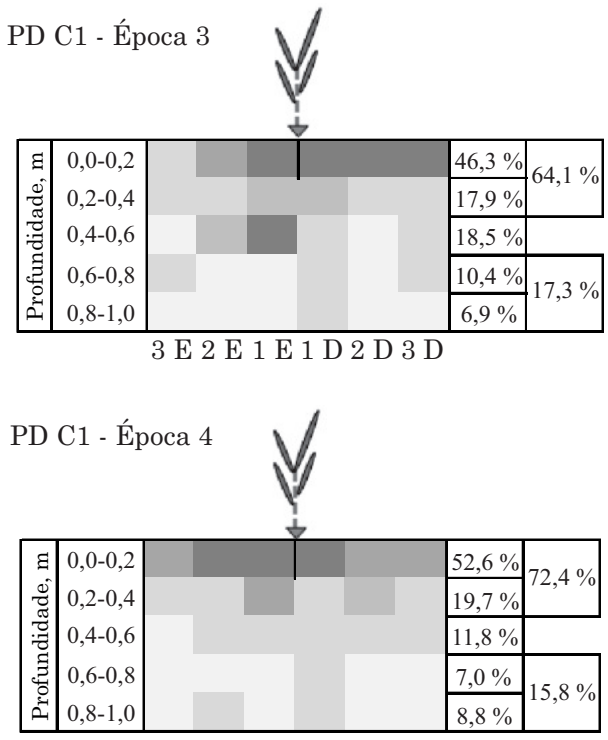

3 E 2 E 1 E 1 D 2 D 3 D

Figura 3. Distribuição do sistema radicular no sistema plantio direto (PD), por camada de solo, nas quatro épocas de amostragem: 1 - máximo deficit hídrico, 2 - início reposição hídrica, 3 - máximo excedente hídrico e 4 - início déficit hídrico, sem calcário (C0) e com 2,0 t ha-1 de calcário (C1) em seis posições: 1D - rente ao lado direito da soqueira; $2 \mathrm{D}$ - $30 \mathrm{~cm}$ à direita da posição $1 \mathrm{D} ; 3 \mathrm{D}-30 \mathrm{~cm}$ à direita da posição $2 \mathrm{D}$; $1 \mathrm{E}$ - rente ao lado esquerdo da soqueira; $2 \mathrm{E}-30 \mathrm{~cm}$ à esquerda da posição $1 \mathrm{E}$; e $3 \mathrm{E}-30 \mathrm{~cm}$ à esquerda da posição $2 \mathrm{E}$.

72 a $75 \%$ de raízes concentradas na superfície, até $40 \mathrm{~cm}$ de solo, na cana-planta, e 70 e $68 \%$, na primeira soqueira. Em outro estudo, Faroni \& Trivelin (2006) observaram mais de $90 \%$ de raízes nas camadas de 0,00-0,20 e 0,20-0,40 $\mathrm{m}$ de profundidade, mas verificaram maior proporção de raízes vivas ou metabolicamente ativas em profundidade, principalmente na camada de 0,40-0,80 m, o que reforça a importância da massa de raízes nas camadas mais profundas.

$\mathrm{Na}$ entrelinha, a $0,60 \mathrm{~m}$ da soqueira, foram observados de 25 a $30 \%$ das raízes. A concentração do sistema radicular da cana-de-açúcar mais próxima da linha de plantas (Posição $1=1 \mathrm{D}+1 \mathrm{E}$ ) justifica a aplicação de insumos, como os fertilizantes, em linha ao lado das plantas, pela maior possibilidade de absorção dos nutrientes fornecidos às plantas (Otto et al., 2009). Entretanto, Costa et al. (2007) observaram que a distribuição horizontal de raízes de cana-deaçúcar pode ser influenciada pela posição em que é aplicada a adubação de soqueiras e pelo efeito do tráfego de máquinas e implementos. Dunbabin et al. (2001) afirmaram que o acúmulo de nutrientes em determinado 


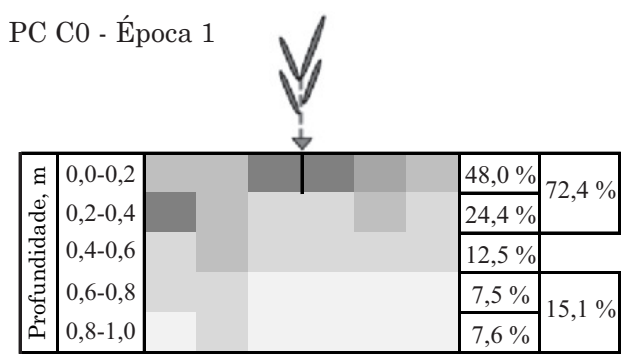

3 E 2 E 1 E 1 D 2 D 3 D

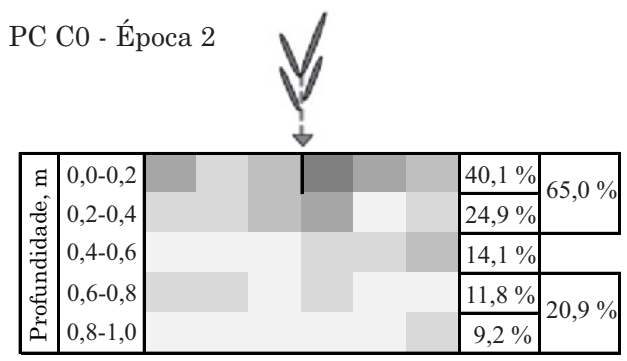

3 E 2 E 1 E 1 D 2 D 3 D

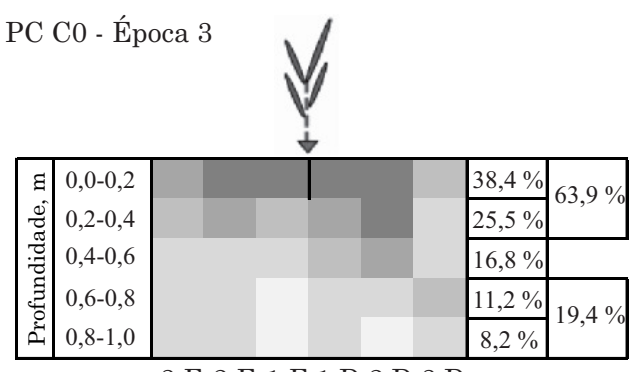

3 E 2 E 1 E 1 D 2 D 3 D

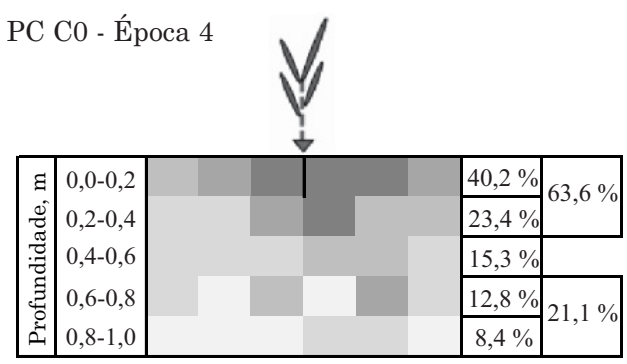

3 E 2 E 1 E 1 D 2 D 3 D

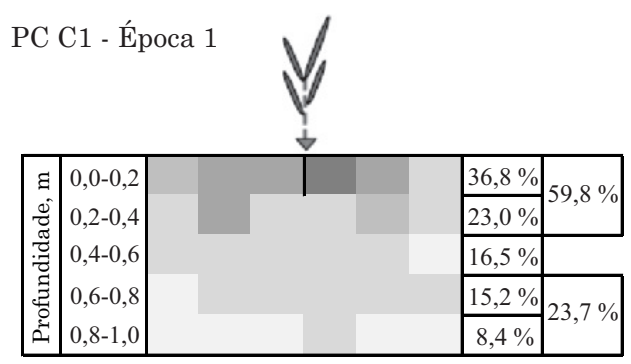

3 E 2 E 1 E 1 D 2 D 3 D

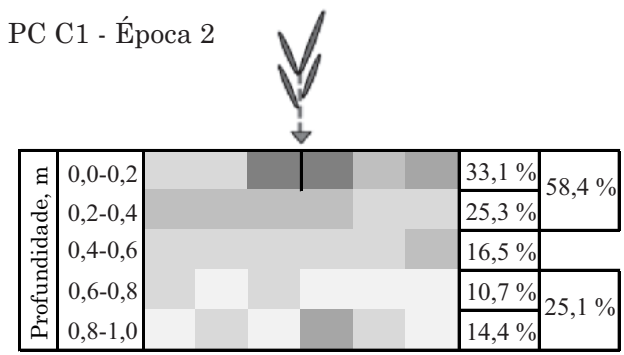

3 E 2 E 1 E 1 D 2 D 3 D

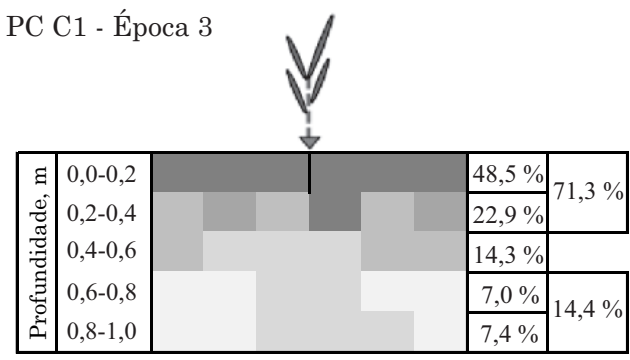

3 E 2 E 1 E 1 D 2 D 3 D

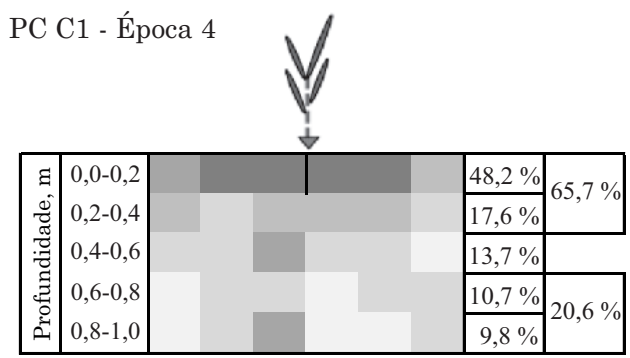

3 E 2 E 1 E 1 D 2 D 3 D

Figura 4. Distribuição do sistema radicular no plantio convencional (PC), por camada de solo, nas quatro épocas de amostragem: 1 - máximo deficit hídrico, 2 - início reposição hídrica, 3 - máximo excedente hídrico e 4 - início déficit hídrico, sem calcário (C0) e com 2,0 t ha-1 de calcário (C1) em seis posições: 1D - rente ao lado direito da soqueira; $2 \mathrm{D}$ - $30 \mathrm{~cm}$ à direita da posição $1 \mathrm{D} ; 3 \mathrm{D}$ - $30 \mathrm{~cm}$ à direita da posição $2 \mathrm{D}$; $1 \mathrm{E}$ - rente ao lado esquerdo da soqueira; $2 \mathrm{E}-30 \mathrm{~cm}$ à esquerda da posição $1 \mathrm{E}$; e $3 \mathrm{E}-30 \mathrm{~cm}$ à esquerda da posição $2 \mathrm{E}$.

local no solo pode proporcionar maior crescimento de raízes, em razão da maior disponibilidade de nutrientes.

O maior acúmulo de biomassa radicular no perfil do solo, na camada de $0,00-1,00 \mathrm{~m}$, foi encontrado na época 3 (máximo excedente hídrico), seguida das épocas 4, 1 e 2 (Quadro 4). Diferenças significativas entre os tratamentos foram observadas apenas na época 1, com C0 apresentando maior biomassa total de raízes $\left(4,8 \mathrm{t} \mathrm{ha}^{-1}\right)$; e na 3 , com o $\mathrm{PC}$ apresentando maior biomassa $\left(5,5 \mathrm{t} \mathrm{ha}^{-1}\right)$. A partir do máximo excedente hídrico, quando a cana-de-açúcar apresenta o máximo desenvolvimento radicular, a cultura perde massa de raízes, atingindo um mínimo quando se inicia o período chuvoso novamente. Otto et al. (2009) também observaram maior massa de raízes entre outubro e fevereiro (época úmida) e diminuição da massa de raízes em junho (época seca).

Como afirmaram Inforzato \& Alvarez (1957), Alvarez et al. (2000) e Vasconcelos (2010), o crescimento das raízes de cana tem influência direta 
Quadro 4. Biomassa total de raízes no perfil do solo por época de amostragem, em todas as posições e na camada de 0,00-1,00 m de solo, e produção média da parte aérea da cana-de-açúcar dos tratamentos sem calcário (C0) e com 2,0 t ha-1 de calcário (C1) e nos tratamentos plantio direto (PD) e plantio convencional (PC)

\begin{tabular}{|c|c|c|c|c|c|c|}
\hline \multirow[b]{2}{*}{ Fator } & \multicolumn{5}{|c|}{ Produção de biomassa total de raíz } & \multirow{2}{*}{ Produção média da parte aérea } \\
\hline & Época 1 & Época 2 & Época 3 & Época 4 & Amplitude & \\
\hline & & & & 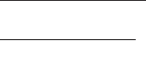 & $\mathrm{ha}^{-1}$ & \\
\hline \multicolumn{7}{|c|}{ Calagem } \\
\hline $\mathrm{Co}$ & $4,826 \mathrm{~b}$ & $3,068 \mathrm{a}$ & $4,910 \mathrm{a}$ & 5,005 a & $2,650 \mathrm{a}$ & 117,33 a \\
\hline $\mathrm{C} 1$ & $3,698 \mathrm{a}$ & $3,554 \mathrm{a}$ & $5,223 \mathrm{a}$ & $4,584 \mathrm{a}$ & $2,106 \mathrm{a}$ & $129,33 \mathrm{a}$ \\
\hline \multicolumn{7}{|l|}{ Manejo } \\
\hline $\mathrm{PC}$ & $4,003 \mathrm{a}$ & $3,444 \mathrm{a}$ & $5,542 \mathrm{~b}$ & $5,003 \mathrm{a}$ & $2,433 \mathrm{a}$ & $120,83 \mathrm{a}$ \\
\hline $\mathrm{PD}$ & $4,521 \mathrm{a}$ & $3,178 \mathrm{a}$ & $4,590 \mathrm{a}$ & $4,586 \mathrm{a}$ & $2,323 \mathrm{a}$ & $125,83 \mathrm{a}$ \\
\hline Época & $4,262 \mathrm{~B}$ & $3,311 \mathrm{~A}$ & $5,066 \mathrm{C}$ & $4,794 \mathrm{BC}$ & & \\
\hline
\end{tabular}

As letras em cada coluna comparam os níveis de cada fator e, quando diferentes, indicam que os valores diferem significativamente pelo teste de Tukey a $10 \%$.

da disponibilidade hídrica no solo, que varia com a época do ano. Também como Alvarez et al. (2000), que trabalharam com cana crua e queimada, neste trabalho os tratamentos não modificaram significativamente o teor de umidade do solo, de forma a alterar a quantidade de raízes e a distribuição do sistema radicular.

Notou-se, entretanto, que a amplitude da biomassa radicular, determinada pela diferença entre o valor máximo e o mínimo do peso total médio de raízes (Quadro 4), foi menor nos tratamentos C1 e PD. A menor amplitude indicou que, nesses tratamentos, as plantas não precisaram emitir muitas raízes e mantiveram a massa radicular mais constante ao longo das épocas com diferentes condições hídricas. Segundo Vasconcelos (2002), a manutenção de grande massa de raízes resulta em grande gasto de energia metabólica e tem consequências negativas sobre o crescimento em altura de plantas e sobre a produtividade. Parte das reservas utilizadas para produção de colmos e folhas poderia ser drenada para o aumento e a manutenção do sistema radicular. Neste trabalho, entretanto, tanto a amplitude de raízes como a produção de colmos (Quadro 4) não apresentaram diferenças significativas entre os tratamentos. No entanto, a produção de raízes apresentou valores máximos significativamente diferentes nos tratamentos $\mathrm{C} 0$ e PC, indicando que esses podem estar drenando reservas para ampliar o sistema radicular, em busca de nutrientes e água. Camilotti et al. (2005) também não observaram efeito de sistemas de manejo no perfilhamento e na produtividade de canade-açúcar em quatro cortes sucessivos.

\section{CONCLUSÕES}

1. As alterações físicas e químicas do solo por influência do PD e da aplicação de calcário não foram suficientes para mudar significativamente o desenvolvimento do sistema radicular da cana-de-açúcar.
2. A cana-de-açúcar manteve, em média, cerca de 4,0 t ha ${ }^{-1}$ de raízes no solo na camada até $1,0 \mathrm{~m}$ de profundidade, explorando grande volume de solo, com 25 a $30 \%$ das raízes na entrelinha (0,60 m da linha) e 15 a $30 \%$ abaixo de $0,60 \mathrm{~m}$.

3. A resistência à penetração e a densidade do solo foram mais elevadas na entrelinha, como consequência do tráfego de máquinas, na camada de 0,00-0,40 m. Na linha, a sulcação cria ambiente com menor resistência à penetração, independentemente do sistema de manejo.

4. O PD e o uso de calcário resultaram em valores mais elevados de atributos de fertilidade relacionados à aplicação do calcário, como V\% e teores de cálcio, apenas na camada superficial.

5. A variação na produção de raízes foi mais influenciada pela condição hídrica do solo do que pelas práticas de manejo. A maior produção de raízes foi observada no máximo excedente hídrico; e a menor, na época de reposição hídrica do solo.

6. As maiores variações na produção de raízes entre épocas foram observadas no PC e sem aplicação de calcário. Os tratamentos PD e com calcário mantiveram a massa radicular com menor variação ao longo das épocas de amostragem.

\section{LITERATURA CITADA}

ALVAREZ, I.A.; CASTRO, P.R.C. \& NOGUEIRA, M.C.S. Crescimento de raízes de cana crua e cana queimada em dois ciclos. Sci Agric., 57:653-659, 2000.

CAMILOTTI, F.; ANDRIOLI, I.; DIAS, F.L.F.; CASAGRANDE, A.A.; SILVA, A.R.; MUTTON, M.A. \& CENTURION, J.F. Efeito prolongado de sistemas de preparo do solo com e sem cultivo de soqueira de cana crua em algumas propriedades físicas do solo. Eng. Agric., 25:189-198, 2005. 
CAMARGO, O.A.; MONIZ, A.C.; JORGE, J.A. \& VALADARES, J.M.A.S. Métodos de análise química, mineralógica e física de solos do Instituto Agronômico de Campinas. Campinas, Instituto Agronômico de Campinas, 1986. (Boletim Técnico, 106)

CARVALHO JÚNIOR, I.A.; FONTES, L.E.F. \& COSTA, L.M. Modificações causadas pelo uso e formação de camadas compactadas e, ou, adensadas em um Latossolo Vermelho Escuro textura média, na região do Cerrado. R. Bras. Ci. Solo, 22:505-514, 1998.

CASAGRANDI, D.V. Preparo mínimo de solos Argissolos para a cultura de cana-de-açúcar. Álcool Açúcar, 8:30$33,1988$.

CINTRA, F.L.D.; IVO, W.M.P.M.; SILVA, L.M. \& LEAL, M.L.S. Distribuição das raízes da cana-de-açúcar em sistemas de cultivo com adubação orgânica e Crotalaria spectabilis. Aracaju, Embrapa-CNPTC, 2006. 20p. (Boletim de Pesquisa e Desenvolvimento, 12)

CONDE, A.J. \& DONZELLI, J.L. Manejo conservacionista do solo para áreas de colheita mecanizada de cana queimada e sem queimar. In: SEMINÁRIO COPERSUCAR DE TECNOLOGIA AGRONÔMICA, 7., Anais... Piracicaba, Centro de Tecnologia Canavieira, 1997. p.193-205.

COSTA, M.C.G.; MAZZA, J.A.; VITTI, G.C. \& JORGE, L.A.C. Distribuição radicular, estado nutricional e produção de colmos e de açúcar em soqueiras de dois cultivares de cana-de-açúcar em solo distintos. R. Bras. Ci. Solo, 31:1503-1514, 2007.

DERPSCH, R.; FRIEDRICH, T.; LANDERS, J.; RAIMBOW, R.; REICOSKY, D.; SÁ, J.C.M.; STURNY, W.G.; WALL, P. \& WARD, R.C. About the necessity of adequately defining no-tillage - a discussion paper. In: WORLD CONGRESS OF CONSERVATION AGRICULTURE, 5., Brisbane, 2011. Proceedings... Brisbane, 2011. p.90-91.

DUNBABIN, V.; RENGEL, Z. \& DIGGLE, A. The root growth response to heterogeneous nitrate supply differs for Lupinus angustifolius pilosus. Aust. J. Agric. Res., 52:495-503, 2001.

FARONI, C.E. \& TRIVELIN, P.C.O. Quantificação de raízes metabolicamente ativas de cana-de-açúcar. Pesq. Agropec. Bras., 41:1007-1013, 2006.

FERNANDES, J.; RIPOLI, T.C. \& MILLAN, M.A. A compactação do solo e a brotação das soqueiras. Álcool Açúcar, 3:12-17, 1983.

FERREIRA, D.F. SISVAR: Um programa para análises e ensino de estatística. R. Sympos., 6:36-41, 2008.

HILL, R.L. \& CRUSE, R.M. Tillage effects on bulk density and soil strength of two Mollisols. Soil Sci. Soc. Am. J., 49:1270-1273, 1985.

INFORZATO, R. \& ALVAREZ, R. Distribuição do sistema radicular da cana-de-açúcar va. 290 , em solo tipo terraroxa legítima. Bragantia, 16:1-13, 1957.
MUTTON, M.A. Efeitos de diferentes sistemas de preparo do solo na cultura da cana-de-açúcar (Sccharum spp. var. Na 5679). Jaboticabal, Universidade Estadual Paulista, 1983. 155p. (Dissertação de Mestrado)

OTTO, R.; FRANCO, H.C.J.; FARONI, C.E.; VITTI, A.C \& TRIVELIN, P.C.O. Fitomassa de raízes e da parte aérea da cana-de-açúcar relacionada à adubação nitrogenada de plantio. Pesq. Agropec. Bras., 44:398-405, 2009.

RAIJ, B.van; CANTARELLA, H.; QUAGGIO, A.J. \& FURLANI, A.M.C. Recomendações de adubação e calagem para o Estado de São Paulo. 2.ed. Campinas, Instituto Agronômico/Fundação IAC, 1996. 285p. (Boletim, 100)

RAIJ, B.van; ANDRADE, J.C.; CANTARELLA, H. \& QUAGGIO, J.A., eds. Análise química para avaliação da fertilidade de solos tropicais. Campinas, Instituto Agronômico de Campinas, 2001. 285p.

RHEINHEIMER, D.S.; SANTOS, E.J.S. \& XAVIER, J.K.F.M. Aplicação superficial de calcário no sistema plantio direto consolidado em solo arenoso. Ci. Rural, 30:263-268, 2000.

SILVA, V.R.; REINERT, D.J. \& REICHERT, J.M. Resistência mecânica do solo à penetração influenciada pelo tráfego de uma colhedora em dois sistemas de manejo do solo. Ci. Rural, 30:795-801, 2000.

STOLF, R. Cultivo mínimo para a cana-de-açúcar. B. Tecnol. Planalsucar, 6:5-42, 1985.

STOLF, R. Teoria e teste experimental de fórmulas de transformação dos dados de penetrômetro de impacto em resistência do solo. R. Bras. Ci. Solo, 15:229-235, 1991.

SANTOS, H.G.; JACOMINE, P.K.T.; ANJOS, L.H.C.; OLIVEIRA, V.A.; OLIVEIRA, J.B.; COELHO, R.M.; LUMBRERAS, J.F. \& CUNHA, T.J.F., eds. Sistema brasileiro de classificação de solos. 2.ed. Rio de Janeiro, Embrapa Solos, 2006. 306p.

TORMENA, C.A.; BARBosA, M.C.; COSTA, A.C.S. \& GONÇALVES, A.C.A. Densidade, porosidade e resistência à penetração em Latossolos cultivado sob diferentes sistemas de preparo do solo. Sci. Agric., 4:95-801, 2002.

TORRES, J.S. \& VILLEGAS, F. Labranza reducida para renovación de plantaciones de caña de azúcar. In: ENCUENTRO NACIONAL DE LABRANZA DE CONSERVACIÓN, 1., Villavicencio, 1998. Anais... Villavicencio, 1998. p.337-352.

van OUWERKERK, C. \& BOONE, F.R. Soil physical aspects of zero-tillage experiments. Netherland J. Agric. Sci., 18:247-261, 1970.

VASCONCELOS, A.C.M. Dinâmica do desenvolvimento radicular da cana-de-açúcar. In: VASCONCELOS, A.C.M. \& MIRANDA, L.D., eds. Dinâmica do desenvolvimento radicular da cana-de-açúcar e implicações no controle de nematoides. 2.ed. Americana, Adônis, 2010. 56p.

VASCONCELOS, A.C.M. O sistema radicular da cana-deaçúcar e a expressão do potencial de produção. STAB . Açúcar Subprod., 21:20, 2002. 